\title{
El carácter del gobierno del Reino Hasmoneo: entre la tradición y el helenismo
}

\section{The character of the government of the Hasmonean Kingdom: between tradition and hellenism}

\author{
Helena Domínguez Del Triunfo*
}

\begin{abstract}
RESUMEN
El reinado de los Hasmoneos se extendió entre los siglos II y I a. C. en la zona de Judea. En un primer momento, bajo la administración ptolemaica primero y, seléucida, después, se irán formando los órganos de poder en la forma que conocemos para la época propiamente hasmonea, que llevarán a la independencia de Judea. El funcionamiento del Reino Hasmoneo, no exento de problemática, se movió entre unas tradiciones orientales, heredadas de la época bíblica y la Ley de la Torá, y una corriente helenizadora. Esta mezcla imprimirá en el reino un carácter peculiar, con unas instituciones en las que se reflejan dos corrientes que convergen para dar lugar a una especie de reino con unas magistraturas antiguas, adaptadas a la moda helenística del momento. Las fuentes que se refieren a todo ello son escasas y, en buena parte, subjetivas. Sin embargo, permiten esbozar un panorama de importancia particular, al suponer un
\end{abstract}

\begin{abstract}
The kingdom of the Hasmonean dynasty spread between 2nd and 1st century $B$. C. in the area of Judah. In a first moment, under the Ptolemaic administration first and the Seleucid one after, the organs of power, as we know them in the Hasmonean period, will be shaped to lead the Jewish independence. The mode of operation of the Hasmonean Kingdom, known not without problem, was carried out between the eastern tradition which was inherited from biblical times and the Law of the Torah and a Hellenizing stream. This mixture will print in the kingdom a peculiar character with institutions which reflects two flows that converge to originate a kind of kingdom with old offices, adapted to the Hellenistic current fashion. The sources that refer to all of this are scanty and, besides, subjective. However, they allow us outline an important panorama, implying the existence of a period of transition
\end{abstract}

* Universidad Complutense de Madrid. E-mail: h-dominguez@ hotmail.com. 
periodo de transición hacia la independencia política judía que determinaría la historia de esta región.

PALABRAS CLAVE: Hasmoneos, Helenización, Macabeos, Sumo Sacerdote, Sanedrín. towards the political Jewish independence, which determine the history of this country.

\section{KEYWORDS:}

Hasmoneans, Hellenisation, Maccabeans, High Priest, Sanhedrin.

\section{INTRODUCCIÓN}

El Reino Hasmoneo existió durante apenas una centuria (168-67 a. C.), entre el reinado del Seléucida Antíoco IV y la dinastía iniciada por Herodes y, aún así, plantea muchos interrogantes. Frente a las posturas que consideran que su importancia apenas fue tal, otros autores han visto en el periodo una época de máximo significado para la creación de la identidad judía, cuestión vigente incluso hasta en nuestros días.

Desde hace largo tiempo se viene cuestionando el carácter del Reino Hasmoneo en un debate que trata, principalmente, de esclarecer dos cuestiones básicas para comprender su funcionamiento: ¿cuál fue su verdadera importancia histórica? $Y$, según sus instituciones, ¿se podría hablar de un estado oriental o, más bien, funcionando según los mecanismos de los reinos helenísticos?

Los pueblos del Próximo Oriente habían experimentado la llegada de asirios, babilonios, persas y, ahora, griegos helenísticos. En este sentido, algunos se preguntan si el fenómeno de la helenización fue, acaso, distinto de la asirianización o el medismo y, por ello, existen corrientes a favor y en contra de ese proceso (Grabbe, 2008: 126).

La mayoría de los investigadores acepta la tesis que propuso Hengel hacia 1969 que afirmaba que los judíos y el judaísmo en Palestina estuvieron muy influidos por el Helenismo desde el siglo III. No así para otros como Feldman, según el cual la influencia griega se produjo sobre todo a nivel cultural, pero no necesariamente en la ideología y creencias religiosas (Feldman, 2006: 4-5).

A partir de las ideas del predominio de las instituciones griegas en el Próximo Oriente nace el concepto alemán de la Verschmelzung o amalgama de culturas. También Tarn y Griffith, en 1952, hablaban de una superposición de lo griego al sustrato indígena. Siguiendo las teorías de Bickerman, Tcherikover (1961), afirma que hubo unos «helenizadores» judíos, concluyendo que el desarrollo de este estado fue una lucha de clases entre las masas (representadas por los Fariseos) y la aristocracia de clase alta y sacerdotes (representados por los Saduceos). En este sentido, apuestan por considerar Judea como un estado helenístico en el ámbito político, que no cultural, y sin comprometer sus principios de tradición judía (Grabbe, 2008: 127). 
En todo caso, afirman, no se puede desvincular la naturaleza del estado Hasmoneo de la situación próximo-oriental en época helenística. La presencia griega se había dejado notar en ciudades mesopotámicas como Babilonia y Uruk, sobre todo tras el paso de Alejandro Magno, intensificándose a partir del siglo III a. C., como atestiguan sus registros (Grabbe, 2008: 137-89). Con el tiempo, la población nativa se mezclaría con la griega, en mayor o menor medida, como ocurrió en la cercana Fenicia, donde aparecieron poleis griegas o, también, en Asia Menor, como ejemplifica Pérgamo, lo que no excluye una continuación de su cultura autóctona (Millar, 1983). En general, los habitantes continuaron con la vida que habían llevado hasta el momento siendo, en todo caso, en las clases altas donde la helenización se dejó sentir de forma gradual.

Por lo general se acepta que la helenización alcanzó sobre todo a los líderes, en parte debido a su posición política, débil, que dependía de las alianzas que pudieran hacer con los Seléucidas. Al ser éstos grecoparlantes, una forma de acercarse a ellos habría sido a través del griego como lengua común y una actitud favorable hacia la cultura y los valores helenísticos. Según Hengel, en aquel momento solo los estados con un ejército armado y equipado a la manera griega, con fortalezas y palacios griegos, una economía eficaz y percepción de impuestos al estilo griego, y su idioma como medio de comunicación exterior, habrían sido competitivos en las relaciones con otras ciudades-estado y otros reinos (Hengel, 2001: 22). Es decir, que los reyes Hasmoneos se habrían visto en la necesidad de aceptar la helenización para sobrevivir en el panorama político. Pero este cambio no tuvo por qué comprometer la continuación de las prácticas y creencias religiosas judías, por lo que es lógico pensar en una convivencia de tendencias (Feldman, 2006: 78, 83).

\section{LAS FUENTES}

Las fuentes disponibles relativas al periodo son escasas, lo que ha impedido contrastar muchos de los hechos en ellas narrados, aunque sea por analogía. Además de algunos escritos históricos judíos y algunos fragmentos de la literatura griega, las fuentes más importantes son los Libros I y II de los Macabeos y las Antiquitates de Flavio Josefo. Pero, además, contamos con la información que recientemente han revelado los Rollos del Mar Muerto, hallados en Qumrán, asociados probablemente a la secta de los esenios (Eshel, 2008).

El Libro I de los Macabeos nos ha llegado por la traducción griega del hebreo y abarca desde el saqueo del Templo de Jerusalén por Antíoco IV Epífanes, en el 169 a. C., hasta el asesinato del Hasmoneo Simón en el 135 a. C. La datación del mismo es de alrededor de esa época, basculando entre los años de Juan Hircano (ca. 135 a. C.) y los de Alejandro Janeo (103 a. C.), quizá en el 129 a. C., lo que, de ser así, situaría al autor en plena revuelta Macabea, por lo que podría haber vivido los hechos narrados (Bar-Kochva, 1989: 162, 168-169).

En cuanto al Libro II se acepta, por lo general, que es un resumen de la obra de Jasón de Cirene. Aquí se narra la época de la crisis interna que vivió Jerusalén 
durante el último año del reinado de Seleuco IV (176 a. C.) hasta la derrota de Nicanor en Adasa. Es, de las dos obras, la que más información aporta sobre los comandantes Seléucidas, así como sobre los asuntos de política y administración externa. Es, además, el primer texto que presenta al Judaísmo y al Helenismo como conceptos opuestos, inventando el término loudaismos y utilizando el de Hellenismos, que sobrepasaba así el ámbito de la lengua, al que se había limitado. Estos dos términos pasarían entonces a presentarse como una nueva forma de oposición, enfrentada a los valores tradicionales (Himmerlfarb, 1998: 28).

El resumen fue un género literario aceptado en época helenística, por lo que no hay que olvidar que parte de la historia reconstruida a partir de II Macabeos podría estar teñida con una pátina helenística. Es decir, el escritor podría estar mostrándose como judío en cuanto a sus creencias pero se estaría expresando de un modo griego o helenístico (Himmelfarb, 1998: 20).

A estas consideraciones se unen otras cuestiones, como la posible falta de objetividad en I Macabeos debido al fervor de su autor, partidario ardiente de los Hasmoneos, a quienes consideraba los líderes para la victoria del «Pueblo Elegido» (Goldstein, 2007: 294). Esta idealización presenta a los Macabeos como los héroes de la Torá, como una familia elegida por Dios para defender la Ley Divina y el Templo de Jerusalén (Murphy, 2004: 65). Por tanto, los detalles que menos interesaban para este discurso quedarían ocultos, idealizando a unos Hasmoneos que, en realidad y, pese a la revolución, actuaban para la administración seléucida (Schwartz, 1993: 309).

Considerando todo ello, la obra de Flavio Josefo aporta luz a todo el asunto. De hecho, es la única fuente de la que disponemos para los acontecimientos después del 134 a. C. Si bien en su Bellum Judaicum se recoge también parte de la Historia de los Hasmoneos, son los Libros XIII y XIV de las Antiquitates los que contienen la mayoría de la información para nuestro estudio.

Josefo descendía por vía materna de la familia de los Hasmoneos y parece que, por conveniencia, se basó como única fuente en Nicolás de Damasco al describir la tortuosa historia de los judíos que llevaría a la «gran revuelta» de su tiempo, en el $66 \mathrm{~d}$. C. Por ello, a veces añade pretextos que presentan el periodo hasmoneo como legítimo y justo lo cual, junto con el hecho de su marcada ascendencia, podría contribuir a reflejar, según Farmer, más el juicio personal del propio Josefo que el popular sobre el legado de Judas Macabeo (Farmer, 1958: 132).

Josefo bebió también de la Biblia, de la tradición griega y de otros escritores como el oriental Beroso (Feldman, 2006: 203), eso sí, para contestar a las críticas contra el Judaísmo, defendiéndolo ante un público de lectores helenísticos o paganos (Josefo, Ant., I, 10). En todo caso, al mezclar la información de Nicolás de Damasco con la de las fuentes griegas, el resultado parece ser una composición llena de contradicciones (Eshel, 2008: 8), a pesar de lo cual es el único testimonio que tenemos para la época.

Existieron otros textos, como los de Polibio y Posidonio, parte de los cuales quedan recogidos en la versión que hizo Nicolás de Damasco que, a su vez, se re- 
cogió en la obra de Josefo (Bellum Judaicum I), por lo que se han perdido en su mayoría. Por otra parte, tampoco hay que olvidar que carecemos de la versión seléucida sobre los acontecimientos (Momigliano, 1989: 115).

\section{EL TERRITORIO}

Desde el 320 a. C., Palestina y Celesiria fueron motivo de conflicto entre los herederos del imperio de Alejandro. Bajo los Ptolomeos (301-198 a. C.), Judea quedó integrada en la provincia de la "Celesiria» (Siria y Fenicia). Ésta se dividió en hiparquías y, a su vez, en meridarquías, dos de las cuales fueron Samaria e Idumea. Dentro de ellas había una serie de nomoi, en terminología ptolemaica, topoi en terminología seléucida. A estas subdivisiones se refiere Josefo (Ant. XIII, 126), que utiliza la terminología ptolemaica, de forma que Judea, uno de los nomos, quedó integrada en dos de las meridarquías, la de Samaria, que unió Judea del norte y la de Idumea, al sur, que constituyó otra, desde el Mar Muerto a los confines de Gaza y Ascalón (Bickerman, 1988: 70, Aperghis, 2004: 270).

Los nomoi tenían bajo los Ptolomeos unos magistrados que actuaban en el ámbito local pero rendían cuentas al sistema central. Pero, si bien esta era la regla en Egipto, Palestina y Siria no tuvieron por qué ser gobernadas y administradas necesariamente como otra región egipcia más (Grabbe, 2008: 175). No conocemos si las tropas reales ocuparon la ciudadela de Jerusalén e impusieron un gobernador real ptolemaico o si se mantuvo un gobierno relativamente autónomo, pero Bickerman (1988) concluye que siguió existiendo un ethnos que, más o menos, se autogobernaba con la Ley de Moisés, y que el Templo se consideró sacrosanto.

Para estudiar la situación de Judea nos ha llegado un documento clave, la carta que el rey seléucida Antíoco III dirigió a Ptolomeo, gobernador de la Celesiria, con respecto a los judíos (Josefo, Ant. XII, 138). Datada en el 198 a. C., año en el que comienza el dominio seléucida en la zona, el texto hace referencia a unas magistraturas judías, entre ellas el Senado, omitiendo información en cuanto a la existencia de otros oficiales ptolemaicos. Por ello, hoy en día se mantienen dos posturas contrapuestas: o bien el Sumo Sacerdote y las asambleas judías se mantuvieron como los verdaderos líderes de Judea en el contexto ptolemaico, como defiende la mayoría de los investigadores (Grabbe, 2008: 186), o bien el gobierno recayó en manos de funcionarios ptolemaicos u otros aristócratas judíos al servicio de los Ptolomeos, a saber, el hiparco o el oikonomos en el espectro económico, como ha defendido Rooke (2000: 265).

En este estatuto, un tanto especial, se observa también el juego de poder que se mantendrá ya entre el rey seléucida y el Sumo Sacerdote de Jerusalén, muy importante en el panorama político. Estas relaciones establecerían una alianza entre ambos poderes, que servirá al rey para conseguir lo que desee y al Sumo Sacerdote y las clases altas para enriquecerse y manejar la política de Judea a su antojo lo cual, en último término, llevará a la intervención directa del poder seléucida y a la revuelta Macabea. El Sumo Sacerdote tendría unas funciones más o menos li- 
mitadas según cada momento por los funcionarios seléucidas (Aperghis, 2004: 287-288) pero, en general, los Seléucidas habrían dado, al menos hasta Antíoco IV, un trato favorable a los judíos. El decreto de Antíoco III sobre los judíos (Josefo, Ant., XII, 145) eximía a los sacerdotes del Templo de Jerusalén de pagar las tasas más humillantes, lo que estaría indicando que había una distinción social dentro de los judíos, estableciéndose un estado de privilegio (Musti, 2006: 193). También la carta a Ptolomeo indica este estatus (Josefo, Ant., XII, 138).

En cuanto a la administración seléucida, ésta parece ser continuadora de la aqueménida puesto que se recupera la satrapía persa, pero aportando también elementos ptolemaicos. La gran extensión del Reino hizo que, al igual que habían hecho los Ptolomeos, los Seléucidas crearan unas subdivisiones similares.

\section{LA «REFORMA HELENÍSTICA» Y EL COMIENZO DE LA DINASTÍA}

El panorama de buenas relaciones cambió súbitamente cuando el seléucida Antíoco IV llegó al poder. Entre sus acciones se encuentra una expedición de castigo contra Jerusalén, la profanación de su templo y la prohibición de las prácticas de la tradición judía (II Macc.). Asimismo, instaló en la ciudadela una guarnición extranjera, donde se nombraron epistatai (administradores financieros del templo) extranjeros. La situación era ya delicada, concretamente desde que el Sumo Sacerdote Jasón había obtenido permiso de Antíoco IV para, hacia el 175 a. C, comenzar a convertir Jerusalén en una ciudad griega, lo que se conoce como la «Reforma helenística». Pero ahora las tensiones entre los judíos y sus autoridades se verían incentivadas como nunca antes.

En el relato bíblico probablemente se produjo una manipulación literaria sobre la figura de Antíoco IV (Weitzman, 2004: 17, 228-230). Es más, puede que su actuación no persiguiera un abandono de las costumbres locales y la asimilación de las griegas, lo cual habría contribuido a unir su imperio, sino que sería una decisión estratégica para solucionar el problema administrativo y someter a un control más estrecho a Judea. Probablemente, también buscó eliminar los conflictos que veía derivados de luchas relativas a la Torá (Murphy, 2000: 67). Por otra parte, debió de existir una parte importante de las clases dirigentes, entre ella sacerdotes, que buscó adquirir una educación griega para igualarse a sus vecinos y superar el aislamiento de los seguidores ortodoxos de la Torá, lo cual fue abriendo una brecha cada vez mayor que dio lugar a disputas por el poder. En II Macabeos $(4,14-16)$ se dice, incluso, que los sacerdotes no se preocupaban ya del servicio del templo, descuidando los sacrificios, deseosos de participar en las costumbres griegas.

A partir del 167 a. C., con una nueva entrada seléucida en la ciudad, se derribaron las murallas de Jerusalén y cambió el estatus del Templo judío, pasando a organizarse la ciudad como una polis griega con el nuevo nombre de «Antioquía en Jerusalén». De esta forma se privaba a los judíos del resto del país de su centro religioso. En cuanto a los funcionarios, se menciona para el 167 a. C. a un oficial 
seléucida que es enviado a Jerusalén, el archon phorologias, con el cometido de imponer los impuestos (Mørklom, 2007: 285). Todo ello unido a las prohibiciones que tuvieran que ver con costumbres judías fue el detonante para que, alrededor del sacerdote Matatías, de la familia de Jehoiarib, se formara un núcleo de resistencia. De esta forma, habían pasado a oponerse dos culturas, dos grupos sociales y dos religiones (Preáux, 1984: 351).

Si bien ésta es la razón principal que siempre se ha esgrimido, para Farmer (1958: 50), que sigue las tesis de Bickerman, el desafío a la Ley de la Torá no tuvo solo esta causa externa sino que, más bien, tuvo sus orígenes en conflictos internos dentro de la comunidad judía. La cuestión debatida habría sido la forma a través de la cual Israel se iba a relacionar con la vida cultural y comercial del entorno helenístico, con su cosmopolitismo, politeísmo y tendencias sincréticas. Generalmente, la actitud de los poderes helenísticos hacia los grupos étnicos fue de tolerancia, triunfando por infiltración y asimilación más que por persecución. Pero en un contexto en el que existía ya un nacionalismo judío éste fue el mayor desafío (Farmer, 1958: 50).

Tras sus primeras acciones Antíoco IV promulgó una amnistía, clima de paz que fue aprovechado por Judas Macabeo para entrar en Jerusalén y restaurar el Templo hacia el 163 a. C. Ese año moría el rey y, después, el regente del pequeño Antíoco V, Lisias, derogó el sistema de la polis, restauró el Templo y anuló la «Reforma Helenística», declarándose la Torá como obligatoria para los judíos (II Macc., 11: 23-6).

\section{EL REINO HASMONEO}

Es éste el contexto de inicio de la dinastía Hasmonea, que llevó a Judea a una independencia de la que no gozaba desde hacía 450 años. Ahora asistiremos a una expansión geográfica sin precedentes, a un crecimiento de la población y a un gran desarrollo religioso, cultural y de reforma social (Wayne Dosick, 2007: 95).

El Libro I de los Macabeos ensalza a la dinastía Hasmonea, lo que no fue sino una estrategia de propaganda, no necesariamente equivalente a una realidad social. Para Schwartz, no es creíble el relato de una familia de sacerdotes armados, como aparece en II Macabeos, sino que sería más bien un grupo de representantes de clases muy diferentes, entre ellas, las grandes familias de terratenientes (Schwartz, 1993: 305-306).

A partir de ahora los reyes seléucidas lucharán por ganarse el apoyo de los Hasmoneos. Éstos, por su parte, se pondrán también ahora del lado de unos aspirantes a reyes seléucidas u otros (Goldstein, 2007: 292-318). Por tanto, si antes habían luchado contra ellos y la helenización, ahora los Hasmoneos dependerán en gran parte del favor de estos reyes para conseguir sus propias prerrogativas.

Judea siguió siendo un Estado súbdito del Reino Seléucida al menos hasta el 140 a. C., cuando la «nación» judía eligió a Simón como Sumo Sacerdote de forma 
independiente al rey Demetrio I, que se vio obligado a confirmarlo en su puesto y garantizar la independencia de los judíos (I Macc., 13: 41-42). Puede que, aunque ésta no fuera completa (Goldstein, 2007: 320), desde entonces el reino fue incrementando su libertad, sobre todo a partir del 129 a. C., cuando el Reino Seléucida perdió su importancia política y los Hasmoneos pudieron entonces extender su dominio en Palestina.

El territorio de los Hasmoneos fue ampliado por Simón a partir del 142 a. C. Hacia el 104 a. C., a finales del reinado de Juan Hircano, incluía Samaria, Galilea, algunas zonas de Transjordania y la mayoría de la llanura costera (Eshel, 2008: 63). El interés por las áreas costeras haría de puntos como Jaffa o Gézer lugares de particular interés en el camino que llevaba a Jerusalén (Levine, 1974: 66), al aportarles un punto de paso comercial a través de ciudades judías. Así controlarían el comercio costero y potenciarían el contacto con los puertos mediterráneos y ciudades griegas, como Delos, Sición, Samos, el territorio de Caria, entre otros, o Esparta, con quien Jonatán el Macabeo mantuvo una relación especial (I Macc.12: 118, Katzoff, 1985). El control sobre Gaza, además, les permitió participar en el floreciente comercio con los árabes, situados al sur (Levine, 1974: 66-67).

En esta serie de conquistas la toma de Torre de Estrato o Cesarea habría sido un paso más a la hora de lograr el sueño de los Macabeos, la unificación o restauración de la Tierra de Israel, que recuperaba así sus límites originales, ampliándolos (Levine, 1974: 68).

\section{EL CARÁCTER DEL REINO HASMONEO}

El Reino Hasmoneo estuvo marcado por una doble tendencia que combinó las instituciones y maneras de dos tradiciones, la bíblica, teocrática y antigua, y la helenística, lo que causaría muchas contradicciones (Momigliano, 1975: 127). Esa connivencia con la administración Seléucida, de la que se beneficiaron, fue uno de los puntos de contacto con la monarquía helenística. No quiere decir esto, necesariamente, que los Hasmoneos renegaran de la tradición sino que, al contrario, las fuentes les presentan como judíos de fe que adaptaron la Ley Mosaica a las circunstancias para conseguir sus propias prerrogativas. Se juega también con la hipótesis de que, quizá, llegaron a alterar incluso las leyes tradicionales para adecuarlas a su comportamiento, de forma parecida a los Tobíadas del siglo III a. C., con quienes guardan paralelos (Schwartz, 1993: 309).

Como se esbozaba al principio, una de las cuestiones más debatidas es si podemos hablar o no del Reino Hasmoneo como si de un Reino Helenístico se tratara, bien sometido a los Seléucidas, bien independiente. ¿Se organizó con unas formas heredadas de la época bíblica o, por el contrario, funcionó como un reino «helenizado»?

Aunque habían empezado sus carreras en oposición a la helenización promovida por Antíoco IV Epífanes, durante el siglo siguiente los gobernantes Hasmo- 
neos se helenizaron de forma que, al final del periodo, que terminó con la revolución de Bar Kochva (132-135 d. C.), la disputa que se mantendrá estará ya muy lejos de ser entre helenizantes y no helenizantes, pasando a ser entre los mismos judíos, más píos u ortodoxos (hasidim) y menos píos (Murphy, 2004: 65).

Volviendo a la helenización, Tcherikover (1964) propuso hace ya varias décadas que las ciudades orientales de época helenística tendrían que cumplir unas condiciones para ser consideradas poleis griegas: la ciudad tendría que cambiar su nombre y tendría que tener el derecho a acuñar moneda propia. Pero la realidad oriental no es la misma que la griega y no hay que buscar una equivalencia completa, ya que las instituciones griegas en algunos casos se solaparon sobre unas realidades orientales preexistentes. No se encontrará una democracia de estilo ateniense, libertad o negociaciones diplomáticas con poderes extranjeros ni una organización militar independiente.

En general, en la ciudad helenística se reconocen unas instituciones de tipo ateniense: asamblea, magistrados y consejo probouléutico (Préaux, 1984: 57) que también pueden detectarse en Judea. Pero, además de estos «requisitos», sería también imprescindible la existencia de un gymnasium y un ephebeion como instituciones educativas municipales, que entrenarían a los jóvenes en la vida ciudadana griega (Tcherikover, 1964: 66). Ambas funcionarían no solo como instituciones culturales sino sobre todo como salto a la ciudadanía, base de la misma.

Jasón, ya citado, asumía que con la creación de la «ciudadanía antioquena» y con su petición de crear un gimnasio Jerusalén se convertiría en polis, lo que no estuvo exento de polémica. Esta acción, junto con las prácticas griegas, como la exposición del cuerpo desnudo en el mismo les parecieron sacrílegas y vergonzosas a los judíos ortodoxos, al menos según II Macabeos (4: 9-16). Pero no tenemos evidencia de ningún gimnasio en Jerusalén u otro lugar de Judea tras los intentos de estos sacerdotes helenizantes de época de Antíoco Epífanes (Feldman, 2006: 77), por lo que podemos pensar que la tradición se impuso en este sentido, al menos entre el pueblo.

Tradicionalmente, el poder en el estado judío se había organizado alrededor de tres esferas de poder de tradición hebrea/bíblica, los Ketarim o «coronas», a saber, el Keter Torah, el Keter Malkhut o gobierno civil y el Keter Kehunah o sacerdocio, que se combinaban fruto de una especie de sanción tanto divina como popular (Elazar y Cohen, 1985: 18).

El sistema, basado en la división de poderes, se rompió cuando los Hasmoneos intentaron combinar los cargos de las esferas religiosa y civil, expandiendo sobre todo el gobierno civil y, no solo eso, sino también aunando las esferas civil y religiosa en un mismo poder. Esto supuso un desafío a la autoridad que la corona de la Torá había tenido en la época anterior y una ruptura del equilibrio.

Durante el periodo Hasmoneo se empezó a incorporar a este gobierno civil, compuesto de magistrados y ancianos, el sacerdocio, por lo que el poder sacer- 
dotal perdió mucha independencia mientras la corona de lo civil, inactiva en la época anterior, adquiría de nuevo poder (Elazar y Cohen, 1985: 114).

Para ello, había que prescindir de una institución propia del grupo de los Fariseos, el «Gran Tribunal», que interpretaba la Ley de la Torá y creía que éste era el poder superior. El grupo opuesto a ellos, los Saduceos, tenía para esas mismas funciones al tribunal del Templo de Jerusalén, lo que a ojos de los Fariseos era considerado una herejía (Finkelstein, 2007: 256), pese a que también los Saduceos seguían la Ley Mosaica y no la Ley Oral (Josefo, Ant. XIII, 294; XX, 199). Por todo ello, los Hasmoneos encontraron apoyo en el grupo de los Saduceos.

Los Saduceos, una alianza entre la aristocracia laica y sacerdotal, grandes terratenientes, jueces, prestamistas, comerciantes (Elazar, 1991: 76) veían con este apoyo la ocasión de enriquecerse con las conquistas y el comercio desarrollado entre los judíos y el mundo griego (Tcherikover, 1961: 261). Los Fariseos, ortodoxos, querían por su parte evitar la expansión del poder civil. Este segundo grupo tenía a los hakhamim en cabeza, sabios pertenecientes a la Keter Torah que buscaron aumentar su influencia constitucional y autoridad.

Por tanto, este debate entre lo tradicional y lo nuevo alcanzó a grupos amplios. Los más ortodoxos mantenían un lazo con la tradición bíblica judía, dando preeminencia a la Ley de la Torá y a los sabios judíos. Por su parte, los Saduceos estaban más inmersos en un mundo griego que había penetrado ya en la vida del Reino, con su gobierno civil, el comercio y la apertura y unas instituciones de corte helenístico.

Así, los Hasmoneos supusieron una ruptura con la tradición. El Levítico (21:4) recoge la amonestación que los líderes Fariseos habrían dirigido a Alejandro Janeo por asumir el poder, indicación de que, para los más ortodoxos, los Hasmoneos no tenían derecho a la corona sacerdotal, que se heredaba por línea davídica, lo cual les capacitaba, únicamente, para conservar el poder civil. En I Macabeos (14: 41) se recoge la afirmación de que se aceptaba a los Hasmoneos, concretamente a Simón, solo hasta que apareciese «un profeta digno de fe». Por ello, Murphy ha interpretado que pese a la aceptación había una conciencia de que las cosas no deberían ser así, de que una parte, incluso puede que dentro de sus defensores, pensaran que Dios restauraría la monarquía davídica y el Sumo Sacerdocio saduceo (Murphy, 2004: 66). Además, parece que los Fariseos tenían gran influencia en el pueblo (Josefo, Ant. XIII, 288). Pero, según Tcherikover (1961: 255-256), la judaización de Palestina que llevaron a cabo los Hasmoneos, según la conocemos, habría tenido que agradar a los Fariseos. Por tanto, se puede aventurar que, quizá, esa judaización no habría sido tan acusada.

El concepto bíblico de las esferas de poder que mantienen un equilibrio se recupera en época hasmonea pero, a diferencia de épocas anteriores, ahora el poder civil pasa a tener mayor relevancia, desarrollando unas instituciones que, a primera vista, parecen ser más propias del mundo griego. Por todo ello, Rajak concluye que en época hasmonea asistimos a un Judaísmo de transición, más que una unión entre Judaísmo y Helenismo (Rajak, 1996: 100-101). 


\section{LOS PRINCIPALES ÓRGANOS DE PODER}

\subsection{El Sumo Sacerdote}

El término comienza a aparecer en la tradición postexílica con las mismas connotaciones que se le dan para épocas posteriores (Brutti, 2006: 58). Si bien en la época anterior aparecían como funcionarios reales de los Seléucidas, con títulos como el de «meridarca» de Judea (Tcherikover, 1961: 237), en época hasmonea controlan ya parte de Palestina sin la intervención exterior, siendo representantes del pueblo judío.

La primera persona con este cargo que se menciona para la época es Jonatán Macabeo (I Macc., 10: 20), líder entre el 160 y el 142 a. C. Josefo (Ant., V, 2) retrata una Jerusalén donde los sacerdotes son líderes, actúan como jueces, conducen el culto y enseñan la ley. De hecho, parece ser que Judea había pasado a ser un estado templario con sacerdote, aconsejado en ocasiones por un consejo, el Sanedrín, formado por ciudadanos judíos, sacerdotes y hombres de leyes (Murphy, 2004: 58). En una época anterior, la carta de Antíoco III a Ptolomeo (Josefo, Ant., XII, 138) no menciona a ningún gobernador único, sino que aparece el término gerousia. Para Grabbe (2008: 190, 231), esta ausencia del Sumo Sacerdote, curiosa, puede significar que las funciones de este personaje se restringirían a culto y administración, mientras que el liderazgo lo ejercería este consejo o, también, que el Sumo Sacerdote estaba siendo incluido, con esta referencia, en el mismo.

En época prehasmonea, cuando el Sumo Sacerdote era elegido por el gobernador seléucida, sus competencias se limitaban al ámbito religioso, mientras que el poder político se repartía entre un consejo. Ahora bien, también hubo Sumos Sacerdotes muy poderosos como Onías o Jasón, precedentes de una figura que, en época hasmonea, aparece en las fuentes ya repetidamente como cabeza del estado. Es en época del Sumo Sacerdote Jonatán cuando se produce este punto de inflexión en la independencia de Judea. Jonatán fue nombrado en su cargo por parte del gobernador seléucida Alejandro Balas en el 152 a. C., reconociéndole tanto líder espiritual de la nación judía como líder oficial político. Desde este momento, los Hasmoneos pasarían a ser súbditos semi-independientes del Reino Seléucida (Stemberger, 1999: 410). Sin un control seléucida tan estrecho, el Sumo Sacerdote aumentó su poder como sacerdote-monarca, en esa línea ya esbozada de la unión de las coronas civil y religiosa.

El ya de por sí amplio tema de la administración se complica según tomemos

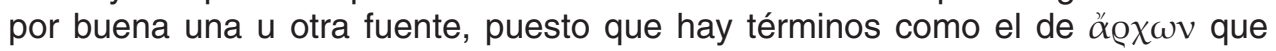
muestran una imprecisión al referirse a los líderes, tendiendo a agrupar varios títulos, solapándose las funciones (Campbell, 2004: 29). O, también, puede que sea una forma de diferenciar a gente del estatuto sacerdotal de otros hombres sabios, todos dentro del Sanedrín.

En todo caso, ¿fue el Sumo Sacerdote, además de una figura religiosa, realmente también una figura política, un líder civil de los judíos de Palestina? En ge- 
neral, se asume una respuesta afirmativa (Grabbe, 2008: 225). De hecho, ya Hecateo de Abdera (FGrHist 264 F 6) describía esta doble personalidad como jueces

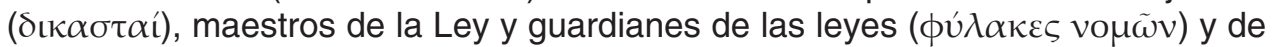
las costumbres ( $\left.\varepsilon^{\prime} \theta \eta\right)$, con una función sagrada; del mismo modo, los judíos tuvieron una autoridad, prostasía, gobernando sobre ellos, que era el Sumo Sacerdote (Hecat. Abd. FGrHist 264 F 6=Diod. XL, 3, 5), líder civil, puesto que sus actividades no se restringían al templo. Con el Sumo Sacerdote Simón aparece también esta palabra (I Macc., 14: 47; II Macc., 3: 4), que le confería poderes para presidir todos los aspectos de la vida religiosa y cívica (Brutti, 2006: 75). Pero según otras informaciones, si bien el Sumo sacerdote tendría la autoridad principal, habría otros jueces con altos cargos, sobre todo para conflictos de gran envergadura (Grabbe, 2008: 231). En este sentido, algunas afirmaciones pueden confundir, como cuando Josefo afirma que un Fariseo, Eleazar, pidió a Hircano que depusiera el cargo de Sumo Sacerdote y se contentara solo con gobernar al pueblo (Josefo, Ant. XIII, 288), lo que puede llevar a pensar en un puesto más bien honorífico.

El Sumo Sacerdocio era un cargo tradicional, reinventado y realzado en el periodo postexílico, con una imaginería del Primer Templo que serviría en la época del Segundo en adelante, adecuándose al momento. Al ser una tradición nativa era más poderosa que las influencias externas a la hora de definir el poder hasmoneo, que elevó, por tanto, una única figura a través del contexto poderoso del culto divino (Bickerman, 1988: 142, Rajak, 1996: 103). De hecho, como revelan los acontecimientos, los Hasmoneos habían llegado a ser Sumos Sacerdotes mucho antes de ser reyes (hasta Simón), aunque con muchos rasgos ya de esa monarquía y su propio ceremonial.

En estos nuevos Sumos Sacerdotes encontramos también muchos rasgos de los monarcas helenísticos. La expedición oriental de Alejandro Magno había animado los aspectos autocráticos militares de su gobierno, lo cual heredaron los Diádocos. El atractivo de la monarquía se aseguraba entonces con la apariencia y ciertos símbolos de realeza. También será propio de los monarcas helenísticos el culto hacia su persona y su poder legislativo como juez, eso sí, en ocasiones junto a un tribunal, el dikasterion (Préaux, 1984: 69), donde encontramos paralelos con el Sumo Sacerdote y su Consejo. No solo en lo institucional, sino que también en su apariencia adoptaron símbolos propios de esas monarquías, como evidencia el permiso que obtuvieron para vestir la púrpura y llevar la fíbula de oro, vestimenta real. Pero para Préaux, si bien la clase sacerdotal estaba ganada por el Helenismo, no estaba asimilada, como tampoco lo estaban los judíos de la Diáspora (Préaux, 1984: 345).

Por otra parte, para ser la cabeza de la nación había que controlar el Templo, puesto que era un estado teocrático y, así, el Sumo Sacerdote aparecería como un intermediario autorizado y legal entre la nación y la divinidad. El tesoro del templo revertía en las arcas del estado, dándole influencia moral y material que se expresaba externamente en diversas riquezas (Tcherikover, 1961: 260).

Así, en su vida privada, este cargo no era austero como cabría esperar de un Sumo Sacerdote judío. De hecho, actuará igual que otros monarcas de la época, 
celebrando banquetes, poseyendo concubinas o persiguiendo a los familiares que consideraban peligrosos para el mantenimiento del cargo (I Macc., 161: 15; Josefo, Ant. XIII, 302, 303, 380). Es decir, se presentaban con el carácter sacro de una institución nativa pero, en la práctica, era un gobierno secular y de tal forma era la vida de la corte, similar a una helenística (Tcherikover, 1961: 252). Este mismo carácter secular causaría un aumento de la oposición de los Fariseos, sobre todo en época de Alejandro Janeo.

Si bien era un estado teocrático, puede observarse un cambio de monarquía

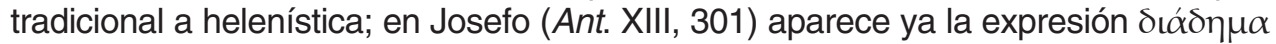
$\pi \varrho \tilde{\omega} \tau о \varsigma ~ \varepsilon ่ \pi ı \tau i \theta \varepsilon \tau \alpha$, «el primero que puso la Diadema sobre su cabeza», en referencia a Aristóbulo I (104 a. C.), que habría transformado el gobierno en un reino.

Si antes veíamos que el peso de la tradición marcó la historia política, también parece que lo hicieron las influencias externas, adaptadas a esta nueva realidad. Como se ha visto, la Revuelta Macabea había arrancado como protesta ante el gobierno seléucida de Antíoco Epífanes pero, sin embargo, la autoridad hasmonea creció gracias a las garantías y privilegios que otorgó esta monarquía seléucida a los miembros de la familia (Rajak, 1996: 102-105). El derecho a vestir la púrpura otorgado a Jonatán, el permiso para reclutar un ejército o el derecho concedido a Simón, por parte de Antíoco, a acuñar moneda, serían algunos de ellos.

\subsection{El Sanedrín}

El estudio del Sanedrín es complicado comenzando por su definición. Bickerman (1988: 143) negó el carácter templario del estado, afirmando que la nación estuvo representada por un Senado desde época seléucida. Dependiendo de los acontecimientos que analicemos, es cierto que, para la época, aparece en las fuentes un Senado o asamblea, a veces coincidiendo con la evidencia de Sumo Sacerdote pero otras, no. Como ejemplo, para el 124 a. C., con Juan Hircano en el poder, los mensajes se enviaban en nombre de «los hermanos de Jerusalén y Judea», en este caso sin hacer referencia al o a los Sumos Sacerdotes.

El reforzamiento de la figura del Sumo Sacerdote al que ahora asistimos ha hecho pensar que, antes de la restauración del templo, el pueblo había estado representado por una gerousia o consejo de ancianos (Brutti, 2006: 88, 91 y Tcherikover, 1964: 72) que también se registra como Sanedrín desde época persa.

Según los Rollos de Qumrán, en el Segundo Templo el rey comenzó a perder privilegios como la poligamia, mientras se expandía el consejo de los 36 sacerdotes, levitas y hombres de ley en una institución nueva, de tipo asambleario (Rajak, 1996: 100). Posteriormente, el consejo seguirá existiendo, bajo varias denominaciones, aunque su nivel de autoridad presenta problemas.

Se ha llegado a plantear, también, que esta institución fue una invención de los rabinos o, incluso, de los investigadores modernos. El término hebreo Sanedrín es un préstamo del ouvédoıvov griego, el Consejo. Por tanto, puede que los autores 
griegos designaran así a un órgano que a sus ojos podría equipararse a su synedrion, aunque no fuera completamente equivalente (Grabbe, 2008: 230).

Según las fuentes que tomemos, podemos aventurar una composición distinta del Sanedrín. Aquellos que afirman la historicidad de las escrituras de la Mishná concluyen que algunos de los Nasi o líderes Fariseos formaron parte del tribunal del Templo o Sanedrín nacional, que se reunían entre el 170 y el 135 a. C. (Finkelstein, 2007: 245-246). Por el contrario, los que confían en el testimonio de Josefo y el Nuevo Testamento creen que la cabeza del Sanedrín fue el Sumo Sacerdote, los Saduceos y otros eruditos, relegando la tradición farisea a la ficción. Este tribunal del Templo era para los Saduceos el árbitro final en las interpretaciones de la Torá, lo que les hizo herejes a ojos de los Fariseos (Finkelstein, 2007: 265). Una cuestión principal sería averiguar si era un tribunal religioso o mixto (civil y religioso).

En el contexto del cambio que supuso la dinastía hasmonea, el Gran Tribunal de los Fariseos (sea o no el Sanedrín) se enfrentó cada vez más al palacio real. Con su Nasi al frente, desarrolló reglas, métodos y procedimientos para interpretar la constitución a su manera, diferenciándose cada vez más de otros grupos (Elazar y Cohen, 1985: 105-106). En época de Antíoco III, hacia el 198 a. C., ejercía como tribunal supremo para todos los asuntos civiles y lo presidía Simón, de la familia de los Oníadas y Sumo Sacerdote, que en Josefo aparecen como «los sabios de Israel» (Josefo, Ant. XIII, 288, 294).

Por tanto, nos encontramos con dos tribunales. Puede que una vez que se destruyera la monarquía el Sumo Sacerdote, líder ahora de la ciudad, pudiera presidir no solo el Tribunal del Templo sino también el Gran Tribunal de Jerusalén Fariseo para cuestiones también de ley civil y militar. Se ha sugerido que sería entonces el momento en el que los Hasmoneos aunaron el gobierno religioso y civil (Finkelstein, 2006: 260).

No hay que olvidar que ya Jasón, en época de Antíoco IV, había sido autorizado para hacer de Jerusalén una polis helenizada, anulando la Ley Judía de esta tierra. Entonces, los problemas públicos se tratarían en la gerousia helenizada, arrebatando toda jurisdicción al antiguo Gran Tribunal Fariseo.

Por ello, los tribunales y el Sanedrín también se confunden. Tras conseguir la independencia, cuando Simón quiso legitimar su poder por no descender de los Saduceos no acudió al tribunal del Templo, compuesto por las cabezas de las familias ricas, como la gerousia helenística, sino a la asamblea compuesta por los sacerdotes, el pueblo, los príncipes y ancianos de Jerusalén (I Macc., 14: 28), muchos de los cuales eran sabios Fariseos, hombres leídos y piadosos sin intereses personales. Finkelstein (2007: 274) cree que, con esta composición, tenía que ser un tribunal donde las facciones fariseas estuvieran unidas, que no podía ser otro que el Gran Tribunal Fariseo. De hecho, esa "gran asamblea», compuesta por un espectro social tan variado, nos hace cuestionarnos si, acaso, sería esa mezcla, la de los eruditos y la de la asamblea, el Sanedrín mismo. 


\subsection{La Gerousia}

Dependiendo del pasaje, encontramos a la gerousia en distintas formas, como su aparición aislada, sin mencionarse al Sumo Sacerdote, que nos da II Macabeos. La cuestión misma de la existencia del Sanedrín ha sido también últimamente, y aún lo es, rebatida, porque implica aceptar las evidencias dadas por la Mishnah, contradictoria, lo que hace pensar que su «creación» podría haber sido una forma que tuvieron los rabinos de legitimar su propia política (Campbell, 2004: 31).

En cuanto a su función hay dos opiniones principales. O bien fue una institución pública para los problemas religiosos que participó también en la vida ciudadana o, por el contrario, fue simplemente un grupo de ciudadanos de edad madura sin carácter oficial o público (Brutti, 2009: 175-176). Aparece también documentada en Josefo por primera vez para el año 200 a. C. (Ant. IV, 186), con un papel gobernante, a veces y, en otras, conectado al Sumo Sacerdote para juzgar casos de gran envergadura transferidos de los jueces locales al Sumo Sacerdote, el profeta y la gerousia (Ant. IV, 218). No solo esto, sino que añade que el rey no tenía nada que ver con el Sumo Sacerdote y el «consejo de senadores» ( $\tau \tilde{\omega} v$ $\gamma \varepsilon$ Quv $\alpha \alpha \sigma \tau \tilde{\omega} \nu)$, lo que hace pensar en un autogobierno para estos asuntos, pese al dominio superior seléucida.

Si bien no sabemos si la gerousía, consejo, Sanedrín y tribunal del Templo son lo mismo, sí sabemos que en época del sacerdote Onías II, hacia el 200 a. C. (Josefo, Ant., XII, 158), la gerousia estaba altamente helenizada y, también, que este sacerdote quería evitar que tuviera autoridad sobre toda la vida religiosa judía. Siguiendo otros pasajes de la Biblia, parece que la gerousia tuvo autoridad para decidir sobre cuestiones sobre daños físicos entre personas, siguiendo una doctrina como la de los Saduceos que observaban la Ley del Talión. En este sentido, Onías II habría querido eliminar este derecho, por lo que se deduce que actuaba como tribunal con amplia jurisdicción (Finkelstein, 2007: 256).

Tenemos también como testimonio la ya citada carta de Antíoco III a Ptolomeo V (Josefo, Ant. XII, 138), donde aparece una gerousia, equiparable a un Senado, y a unos sacerdotes, escribas del Templo y tañedores sagrados. Pero no aparece el Sumo Sacerdote, puesto que puede estar incluido en ese cuerpo. Por primera vez se menciona este órgano para asuntos similares, sirviendo de precedente para el reinado de sacerdotes helenizados y época de los primeros Hasmoneos. Según este ejemplo, dirigiría la política exterior y los pactos lo cual, unido a la ausencia del Sumo Sacerdote, lleva a pensar que la comunidad estaba más liderada por ésta, pudiendo ser el mismo Sanedrín-tribunal ya analizado.

En aquella ocasión había actuado como la autoridad máxima representando a los judíos. Según Tcherikover esta institución, se llamase ya gerousia o no, sería en época hasmonea la versión evolucionada de una institución anterior similar. Así, se habría convertido en una gerousia o Hever ha Yehudim más amplio con una mayor presencia de la aristocracia judía saducea, que apoyaba los ideales del estado y las guerras de conquista (Tcherikover, 1964: 72). También a nivel interno 
sería toda una autoridad, ya que ratificaría incluso a Simón el Macabeo ( I Macc, 14: 27, 14: 41), dando una pátina política a los referentes constitucionales básicos de la Torá (escrita y oral) que había sido aceptada en la época anterior (Elazar y Cohen, 1985: 105).

¿Había alcanzado la helenización a estos órganos? Por una parte, el hecho de que en el decreto de Antíoco III (Josefo, Ant., XII, 145) aparezca el ethnos bárbaro indica que el rey no se estaba refiriendo a Jerusalén como a una polis griega. Sin embargo, en época de Antíoco IV los helenistas judíos habían ganado posiciones y, de hecho, aparece funcionando la gerousia en la polis establecida con Jasón, donde Menelao es acusado por tres miembros de la misma (II Macc. 4: 4350). Además, otras referencias indican que también sería un cuerpo gobernante de los judíos en época ya hasmonea (II Macc. 11: 27; III Macc. 1: 6-8) lo cual, en opinión de Grabbe, demuestra sobradamente la existencia de este cuerpo en la ciudad, rasgo helenístico de la época de Jasón (Grabbe, 2008: 231) y, probablemente, también después.

Otros autores, como Campbell (2004: 32-33), ven un panorama bien distinto, en el que la gerousia tendría un papel más administrativo que legislativo o judicial. Según esto, cuando encontramos referencias en I Macabeos o en otras fuentes de reyes o Sumos Sacerdotes que se dirigen a los ancianos no habría que pensar en hombres elegidos para un cargo, sino en gente dignificada por riqueza, nacimiento o antigüedad, unos presbíteroi o ancianos que aconsejarían al gobernador.

Esta tesis encuentra acomodo en la tradición de la sociedad israelita, tribal y patriarcal, representada por los ancianos (Campbell, 2004: 21-23) y concuerda con la aparición del término «presbíteros» para época de dominación seléucida (I Macc, 1:26; 7: 33; II Macc., 5:13; 8: 30; 13:33; 14:37). Bajo la monarquía podrían haber perdido poder en favor de los funcionarios reales y aparecerían en las fuentes como el título de algún funcionario del gobierno, no necesariamente anciano ya, con funciones jurisdiccionales en las comunidades judías (Harvey, 1974: 319-20).

Por todo ello, la conclusión a la que llega Brutti (2009) parece bastante reveladora. En el periodo Seléucida, antes de la dinastía de los Hasmoneos, el significado del papel del Sumo Sacerdote había declinado y era entonces ya menos representativo de la gente al depender del gobierno seléucida. En este contexto, la gerousia habría asumido este papel para la comunidad judía, dándole una representación externa. Esta importancia nueva podría estar también relacionada con los vínculos de amistad establecidos entre judíos y espartanos, lo cual tiene su importancia puesto que la gerousia de Esparta es la que mejor se conoce (Katzoff, 1985).

Posteriormente, en época hasmonea, en las cartas del Sumo Sacerdote Jonatán a los espartanos (I Macc., 12: 6) aparece el ethnos de los judíos junto con la gerousia como los remitentes pero, sin embargo, tras la muerte de Jonatán, la respuesta espartana no menciona ya a esta gerousia, sino a unos $\pi \varrho \varepsilon \sigma \beta u ́ \tau \varepsilon \varrho o l ~(I$ Macc., 14: 20). Esto puede hacer pensar que, al haber desaparecido el término de 
la correspondencia de la época, o bien era una institución no muy definida o bien, con el Sumo Sacerdote, se había convertido de nuevo en ese grupo de gente que tenía que ser respetada, como ya se citó anteriormente, más que un cuerpo oficialmente constituido de gobierno (Campbell, 2004: 95, Brutti, 2009: 180-181). Pero tampoco podemos tomar esta hipótesis como absolutamente irrefutable. Es cierto que hay una gran confusión entre los diversos órganos, dudando incluso de si fue el mismo o no. Pero, lo que sí conocemos, son las funciones ya analizadas, que se movieron entre la tradición y el helenismo, de una o varias instituciones a las que las fuentes no aciertan a dar un solo nombre.

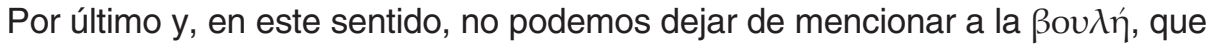
aparece también en nuestras fuentes y que se confunde con el Sanedrín, la gerousia y el synedrion. Sin embargo, Josefo utiliza el término solo para el estado judío de época romana (Bell. Jud., XIV, 168), además de otros como arcontes y bouleutaí mezclando, pues, magistraturas tales como «consejero» y «gobernante» (Tcherikover, 1965: 68).

Se podría pensar que la aparición de la boulé indicaría ya de por sí la existencia de una organización políada pero, de ser así, tendría una autoridad solo para Jerusalén y su vecindad, que no es el caso, puesto que $\chi \omega \hat{\varrho} \alpha$ de Jerusalén se extendía más allá de la propia ciudad, incluyendo incluso toda la Palestina judía (según se deduce de Bell. Jud. V, 532). Si fuera así, este órgano representaría a toda la nación (Tcherikover, 1964: 68).

En época romana la boulé (Bell. Jud., III, 51) aparece representando a la población frente a las autoridades romanas y negociando con ellas, lo que hace pensar que el Sanedrín funcionaría más como un órgano de justicia, al menos por entonces. Basándose en que la situación religioso-legal en Israel del momento no permitía la división de autoridad para las funciones políticas y religiosas puede que, incluso, ambas instituciones hubieran sido la misma (Tcherikover, 1964: 70-71).

Otros autores como Büchler o Finkelstein (1950) distinguen entre el Sanedrín, encabezado por el Sumo Sacerdote, el Beth-Din de los Fariseos, con otro líder, y el consejo. Pero quizá desentrañar este asunto tan caótico no sea tan difícil. Conocemos que en época hasmonea el Sumo Sacerdote pasó a dominar el Gran Tribunal de mayoría farisea, el tribunal del Templo y, además, aparece con Jasón una gerousia helenizada con las funciones del Gran Tribunal. Cabe preguntarse cómo se relacionaron el consejo de Josefo y el Sanedrín del Nuevo Testamento, ambos mencionados junto con el Sumo Sacerdote, si uno sustituyó al otro, etc. O, también, puede que en realidad nos hallemos ante un mismo organismo que primero se llamara Gran Tribunal y, posteriormente, fuera sustituido por el Sanedrín, que aparecería con las diversas denominaciones de consejo, entre ellas Sanedrín,

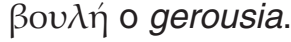




\section{CONCLUSIONES}

Al inicio del presente estudio se analizaban las fuentes historiográficas disponibles de mayor notoriedad para estudiar el Reino Hasmoneo, con el problema, aún presente, de la escasez, veracidad, objetividad y finalidad de los autores de las mismas. Por tanto, si bien se acepta que son, por lo general, válidas, hay que tener siempre presente el sesgo al que podemos estar asistiendo al utilizarlas, sobre lo cual existen aún posiciones enfrentadas.

Por otra parte, su carácter poco descriptivo apenas permite debatir sobre el contenido de los términos, por lo que se debe recurrir a una labor de deducción a través de los hechos que sí conocemos para dilucidar, así, la función que pudieron tener las instituciones y magistraturas. De esta forma, muchas veces hay que limitarse a la sistematización del conocimiento que tenemos sobre las mismas, sin que éste llegue a ser pleno, permitiendo pocas veces poco más que dar nombre a las instituciones y aventurar su función. No solo carecemos de información completa y fiable del funcionamiento de la dinastía sino que, además, para algunos de los gobernantes más importantes, como Judas, Jasón o Simón apenas tenemos información sobre su reinado.

Con los datos analizados, se pueden deducir, sin embargo, varias cosas. Una de las cuestiones más interesantes es que el gobierno hasmoneo se movió entre lo antiguo, con un ethnos judío que poseía unas instituciones que lo legitimaban, la Ley de Moisés y el gobierno del templo, y lo moderno, que vino dado por la corriente helenizadora del momento.

Pero esta misma naturaleza del estado hasmoneo plantea varios problemas en su estudio, uno de los cuales surge al intentar superponer en Judea unas instituciones griegas sin tener en cuenta el sustrato anterior, como se ha observado a lo largo del presente texto. Otro de los problemas es la denominación misma de estas instituciones en Judea y su equiparación con las griegas o la coexistencia de las mismas con los Ketarim bíblicos. La cuestión terminológica es, por tanto, otro de los inconvenientes presentes a la hora de realizar una descripción detallada, puesto que no se puede hacer una comparación absoluta. Las instituciones se conocen mejor por su carácter, como se ha analizado, que por su equivalencia total con una realidad, la griega, que conocemos mejor.

Si bien no fueron equivalentes, tampoco hay que afrontar el estudio partiendo de la base de que Helenismo y Judaísmo, Helenismo y Torá o cualquiera de estas dicotomías fueron incompatibles; ambas tradiciones llevaban conviviendo de forma pacífica, mezclándose y modificándose mutuamente, desde la época de Alejandro Magno (Jordan, 1911: 298).

La influencia griega se puede observar, además de lo aquí analizado, en otras instituciones como el ejército, que resultó ser una copia a pequeña escala del ejército Seléucida (Bar-Kochva, 1989) o en la mera utilización de nombres griegos por parte de los gobernantes Hasmoneos, como el de Aristóbulo I (104 a. C.), remarcando su carácter de «filoheleno» y su no descendencia del linaje davídico 
(Murphy, 2004: 6). A la vez, el Judaísmo se vio influido por esta órbita, pero sin comprometer lo autóctono. Así lo ejemplifica el hecho de que se polarizaran unas tendencias, más o menos ortodoxas, dentro del Judaísmo, o el establecimiento de celebraciones judías institucionalizadas como el Hannukah, modelada a partir del festival bíblico de los Tabernáculos así como, también, la utilización por parte de los últimos Hasmoneos de una escritura paleo-hebrea, arcaizante, en sus acuñaciones monetarias (Weitzman, 2004: 232).

Esta parcela del estudio, que conocemos mejor, permite afirmar que, en este acercamiento al sistema helenístico, se produce una confusión de las formas tradicionales con las contemporáneas, volcadas al Helenismo no solo en el ámbito cultural, sino también en el político. La que se podría considerar como una pequeña y, aparentemente, insignificante nación, había entrado ahora en contacto con los grandes imperios mundiales, lo que determinaría su futuro y el de sus gentes (Jordan, 1911: 295), de una forma que, eso sí, aún hay que detallar para comprenderla del todo.

\section{BIBLIOGRAFÍA}

APERGHIS, G. G., The Seleukid Royal Economy. The finances and financial administration of the Seleucid Empire. Cambridge: Cambridge University Press, 2004.

BAR-KOCHVA, B., Judas Maccabaeus. The Jewish struggle against the Seleucids. Vols. I-II. Cambridge: Cambridge University Press, 1989.

BICKERMAN, E. J., The Jews in the Greek Age. London: Harvard University Press, 1988.

BRUTTI, M., The Development of the High Priesthood during the pre-Hasmonean Period. Leiden-Boston: Brill Academic Publishers, 2006.

CAMPBELL, R. A., The elders: seniority within earliest Christianity. London: T\&T Clark Ltd., 2004.

ELAZAR, D. J. (ed.), Authority, Power and Leadership in the Jewish Polity. Cases and Issues. Maryland: The Jerusalem Center for Public Affairs. University Press of America, 1991.

ELAZAR, D. J. y Cohen, S. A., The Jewish Polity. Jewish political organization from Biblical times to the present. USA: Indiana University Press, 1985.

ESHEL, H., The Dead Sea Scrolls and the Hasmonean State, Cambridge: William B. Eerdmans Publishing Company, 2008.

FARMER, W. R., Maccabees, Zealots, and Josephus. New York: Columbia University Press, 1958.

FELDMAN, L. H., Judaism and Hellenism Reconsidered. Leiden-Boston: Brill Academic Publishers, 2006.

FINKELSTEIN, L., «The men of the Great Synagoge (circa 400-170 B. C. E.)». En Davies, W. D. y Finkelstein, L. (eds.), The Cambridge History of Judaism. Volume Two, The Hellenistic Age, Cambridge: Cambridge University Press, 2007, pp. 245-276.

GOLDSTEIN, J. A., «The Hasmonean revolt and the Hasmonean dynasty». En Davies, W. D. y Finkelstein, L. (eds.), The Cambridge History of Judaism. Volume Two, The Hellenistic Age, Cambridge: Cambridge University Press, 2007, pp. 292-351.

GRABBE, L., A History of the Jews and Judaism in the Second Temple Period. Vol. 2: The Coming of the Greeds: The Early Hellenistic Period (335-175 BCE). London: T\&T Clark, 2008.

HARVEY, A. E., «Elders». Journal of Theological Studies, 25 (1974), pp. 319-20.

HENGEL, M., Judentum und Hellenismus: Studien zu ihrer Begegnung unter besonderer Berücksichtigung Palästinas bis zur Mitte des 2 Jh.s v. Chr. Tübingen: Mohr, 1969. 
HENGEL, M., «Judaism and Hellenism Revisited.» En Collins, J. J. y Sterling, G. E. (eds.), Hellenism in the Land of Israel, Notre Dame: University of Notre Dame Press, 2001, pp.6-37.

HIMMELFARB, M., «Judaism and Hellenism in 2 Maccabees». Poetics Today, 19 (1) (1998), pp. 19-40.

KATZOFF, R., «Jonathan and Late Sparta». The American Journal of Philology, 106 (4) (1985), pp. 485-489.

JORDAN, W. G., «The significance of the Maccabean Period». The Biblical World, 38 (5) (1911), pp. 294-305.

LEVINE, L. I., «The Hasmonean conquest of Strato's Tower». Israel Exploration Journal, 24 (1974), pp. 62-69.

MILLAR, F., «The Phoenician Cities: A Case-Study of Hellenisation», Proceedings of the Cambridge Philological Association 209 (1983), pp. 55-71.

MOMIGLIANO, A., Alien Wisdom: the limits of Hellenization. Cambridge: Cambridge University Press, 1975.

MØRKLOM, O., «Antiochus IV». En Davies, W. D. y Finkelstein, L. (eds.), The Cambridge History of Judaism. Volume Two, The Hellenistic Age, Cambridge: Cambridge University Press, 2007, pp. 278-291.

MURPHY, F. J., "Second Temple Judaism». En Neusner, J. y Avery-Peck, A. J. (eds.), The Blackwell Companion to Judaism, Oxford: Blackwell Publishing Ltd., 2004, pp. 58-77.

MUSTI, D., «Syria and the East». En Walbank, F. W. (ed.), The Cambridge Ancient History. Second Edition. Volume VII, part I. The Hellenistic World, Cambridge: Cambridge University Press, 2006, pp. 175-220.

PRÉAUX, C., El mundo helenístico. Grecia y Oriente (323-146 a. C.). Vols. I y II. Labor, Barcelona, 1984.

RAJAK, T., «Hasmonean Kingship and the Invention of Tradition». En Bilde, P. Engberg-Pedersen, T., Lannestad, L. y Zahle, J. (eds.), Aspects of Hellenistic Kingship. Studies in Hellenistic Civilization 7, Aahrus: Aahrus University Press, 1996, pp. 99-115.

ROOKE, D. W., Zadok's Heirs: The Role and Development of the High Priesthood in Ancient Israel. Oxford: Oxford University Press, 2000.

SCHWARTZ, S., "A note on the social type and political ideology of the Hasmonean family». Journal of Biblical Literature, 112 (2) (1993), pp. 305-309.

STEMBERGER, G., «The Saducees - their history and doctrines». En Horbury, W, Davies, W. D. y Sturdy, D. (eds.). The Cambridge History of Judaism. Volume Three, The Early Roman Period, Cambridge: Cambridge University Press, 1999, pp. 428-443.

TCHERIKOVER, V., Hellenistic civilization and the jews, Philadelphia: The Jewish Publication Society of America. The Magnes Press, The Hebrew University, 1961.

TCHERIKOVER, V., «Was Jerusalem a 'Polis'?». Israel Exploration Journal, 14 (1964), pp. 61-78.

WAYNE DOSICK, R., Living Judaism. The Complete Guide to Jewish Belief, Tradition, and Practice. HarperCollins e-Books, 2007.

WEITZMAN, S., «Plotting Antiochus's Persecution». Journal of Biblical Literature, 123 (2) (2004), pp. 219-234. 